Keio J. Med: 20: 143-152, 1971

\title{
ANGIOTOMOGRAPHY IN CEREBRAL ANGIOGRAPHY
}

\author{
SHIGEO TOYA,* TOHRU NAKANISHI,* and IKURO MURASE** \\ Division of Neurosurgery, Department of Surgery, School of Medicine, \\ Keio University, Tokyo, Japan, and Saiseikai Utsunomiya Hospital, \\ Tochigi Prefecture, Japan
}

(Received for publication August 16, 1971)

\begin{abstract}
Almost one-half century has elapsed since Monitz ${ }^{3}$ set out cerebral angiography. While the progress during this period was quite remarkable, more precise interpretations are required along with the developement of each of the related field. For the solution of problems such as overlapping of the vascular system each other or with bone density giving difficulty for interpretation, subtraction method, stereoscopic radiography and tomography were developed.

Since Rocca et al 5 attempted cerebral angiotomography several reports on this method appeared in Europe. ${ }^{1,4,6,7}$ In Japan, no report is yet available on this method, probably due to the requirement of proper apparatus for radiography.

Using Princeps 50 apparatus for cephalography, an apparatus quite suitable for tomography, cerebral angiotomography was performed in 63 cases. The purpose, method, and findings will be discussed in this paper.
\end{abstract}

\section{PURPOSE}

1) Interpretation of deep cerebral vein especially internal cerebral vein and small inflow veins.

2) Clearer demonstration of the relationship between cerebral aneurysm and surrounding blood vessels, based on the tomogram on the plane containing aneurysm and its parent vessel, for reference to the operative approach.

* Division of Neurosurgery, Department of Surgery, School of Medicine, Keio University, Tokyo, Japan.

** Saiseikai Utsunomiya Hospital, Tochigi Prefecture, Japan. 
3) Confirmation of the actual state of arteriovenous malformation in which the presence of drainage vein into the deep cerebral vein was doubted.

4) Detection of unclarified microangioma by the ordinary technique of angiography (subsequently called standard cerebral angiography).

5) Differentiation of the branches of main intracranial arteries such as anterior cerebral artery and middle cerebral artery. Separated interpretation of anterior cerebral artery in the lateral view.

\section{MATERIALS}

Over a period of two years and 6 months from January 1968 to June 1970 , cerebral angiography was performed in 1100 cases at Saiseikai Utsunomiya Hospital.

Angiotomography was carried out in 63 cases, 36 cases of cerebral vascular diseases, 5 cases of head injury, 5 cases of brain tumor, 2 cases of developemental anomaly, 2 cases of cerebral palsy, 6 cases of epilepsy and 7 miscellaneous cases.

\section{METHOD}

Princeps 50 apparatus for cephalography was used. The angle of swing of $\mathrm{X}$-ray projection was $30^{\circ}$ and an exposure time 1.2 second.

Cerebral angiography was at first conducted by the standard technique and method of radiography. Developement was immediately carried out. When the need of angiotomography was suggested for accurate diagnosis based on the $\mathrm{X}$-ray film obtained, angiotomography was carried out taking into consideration of the general condition of the patient.

When the indication of angiotomography is present, the apparatus for the support of the X-ray tube and cassete was set for tomography without changing position of the patient. The support of the head was exchanged with a plastic support. Six to eight $\mathrm{ml}$ of contrast medium were used for one procedure. In children, this dose was adjusted according to body weight.

In the angiotomography of the arterial phase swing of projection and exposure was started about 0.5 second after the beginning of injection of contrast media. In the venous phase of angiotomography, an exposure was started 2 second after the injection. The tomographic plane was determined as a rule based on measurement on the aimed site using the external auditory meatus, external occipital tubercle and nasion as the standard point in antero-posterior or lateral view of the standard cerebral angiography. 
RESULTS

\section{a) Normal findings}

In the lateral view of the median sagittal angiotomogram, anterior cerebral artery is distinctly visuarized from $\mathrm{A}_{2}$ portion to the peripheral portion except for $A_{1}$ portion. In the standard cerebral angiogram, peripheral portion of anterior cerebral artery overlapping with branches of middle cerebral artery frequently gives difficulty for interpretation. In angiotomography, however, visualization of the anterior cerebral artery alone is possible, so that the interpretation becomes quite easy (Figs. 1a and 1b).

Attempts were made to visualize the lenticulostriate artery in antero-posterior angiotomogram. This was performed in 10 cases with normal course of this artery in standard angiogram. Visualization of lenticulostriate artery was possible in only 4 cases in the angiotomogram (Table 1 ). In the table $1,(+)$ indi-

Table 1

Visualization of lenticulostriate arteries

\begin{tabular}{c|c|c}
\hline \hline standard angiography & angiotomography & \\
+ & - & 6 \\
+ & \pm & 2 \\
\pm & + & 2 \\
- & - & 1 \\
& + & 0 \\
\hline
\end{tabular}

(t) definite visualization, $( \pm)$ somewhat indefinite visualization,

(-) failure of visualization.

cates definite visualization, ( \pm ) somewhat indefinite visualization, and $(-)$ fallure of visualization or absence of lenticulostriate artery.

Angiotomography of deep cerebral vein was carried out in 45 cases. All these were carried out through carotid artery puncture and tomographic plane was median sagittal plane. Internal cerebral vein is visualized as shown in Fig. 2 and 3, without being interrupted by cortical veins in the lateral projection. It is possible to visualize deep cerebral vein alone. In 6 cases standard angiogram failed to give distinct picture but tomography gave good visualization.

b) Abnormal findings

\section{Aneurysm}

Angiotomography was performed in 8 cases ( 5 cases of anterior commu- 
nicating artery aneurysm, 1 case of anterior cerebral artery aneurysm, and 2 cases of internal carotid artery aneurysm). In anterior communicating artery aneurysm and anuerysm of distal portion of anterior cerebral artery angiotomography on the median sagittal plane visualized only the blood vessels around the aneurysm including parent vessels. This was useful as reference for operative approach. Fig. 4 shows a clearer demonstration of an aneurysm of distal portion of anterior cerebral artery. $\Lambda$ s in internal carotid artery aneurysm seen in the Fig. 5, especially in lateral view the presence of bleb and shape of the aneurysm became clear. Based on the irregulnrity on the wall of the aneurysm, site of rupture was presumed.

Arterio-venous malformation

Whether the drainage vein is related to deep cerebral vein or not is a serious problem for the decision of operative indication. Tomography was performed in 3 cases of arteriovenous malformation. Especially in a 20 years old male with arteriovenous malformation in the left parietal region, inflow into deep cerebral vein was seriously doubted in standard angiogram but confirmation was obtained through tomography. Microangioma frequently escaped the detection in standard angiogram or gave difficulty for confirmation. Fig. 6a shows a standard angiogram of a 42 years old male. Presence of microangioma in the peripheral portion of right lenticulostriate artery was suspected. This was established through tomography (Fig. 6b).

Neoplasma

Cases of meningioma were selected for study among brain tumors. In a case of olfactory groove meningioma and of right frontal convexity meningioma, displacement and deformity of internal cerebral vein was distinct in the tomogram. In latter case, angiotomogram through the plane passing the tumor was obtained and the paucity of vascular shadow within the tumor was predicted. Based on the operative and histological findings, this was found to be a fibroblastic meningioma with poor vascularity.

Congenital anomalies

In cases of cavum veli interpositi and those of cyst of septum pellucidum, cerebral angiography was carried out following to pneumoencephalography to study the mutual relationship between vascular system and subarachnoid space. In cases of cavum veli interpositi when the lesion was clarified by pneumoencephalotomography, angiotomography of venous phase on the median sagittal plane made the diagnosis more definite through confirmation of internal cerebral vein running through the dilated arachnoid space. 


\section{DISCUSSION}

Many method are available in the neurological X-ray diagnosis, besides plain X-ray film of the skull. Among the method of cerebral angiography, standard technique, serial angiography and tomography are available. Subtraction method and harmonization method are also available as necessary. As the indication for angiotomography, the diseases described above are regarded as important by the authers. Du Boulay ${ }^{1}$ also suggested as the application and purpose of angiography as follows.

(1) Differentiation of external and internal carotid branches after common carotid puncture.

(2) Clearer demonstration of tumors and vascular lesions where they are obscured by bone near the skull base.

(3) The demonstration of lingual, facial, maxillary and orbital vessels, particularly in tumor cases.

(4) To give additional information as to the exact depth and site of a lesion with reference to the skull.

While no essential difference is found in the purpose of angiography between the authers and other workers, local and more precise intracranial findings represent the aim of our study.

While the angle of swing and time of exposure in angiotomography should naturally vary according to the apparatus used, the angle of $15^{\circ}$ was considered adequate by $\mathrm{Du}$ Boulay ${ }^{1}$ and $35^{\circ}$ by Rosadini. ${ }^{7}$ As was already presented, ${ }^{8}$ the authers considered $30^{\circ}$ adequate, using 1.2 second as exposure time.

It is possible only with tomography to see the course of anterior cerebral artery alone in lateral view. With the use of this procedure, the course of peripheral portion beyond $A_{2}$ portion of anterior cerebral artery frequently giving rise to difficulty for interpretation in standard angiogram due to overlapping with the peripheral branch of middle cerebral artery may be distinctly visualized.

As to lenticulostriate artery, the decision on the tomographic plane is extremely difficult, in view of the course, and it was not possible to visualize to whole course in one tomogram. As we have already presented, ${ }^{9}$ however, the significance of tomography is extremely great when anomalies of vascular system related to lenticulostriate artery.

As to the diagnostic value of deep cerebral vein, reports by Johansen² and Wolf ${ }^{10}$ are available, and venography has become a routine procedure in cerebral angiography at present. Deep cerebral vein such as internal cerebral vein, moreover, are located on the midline and suitable for tomography with regard to 
anatomical position and course. In the result of the authers, visualization of internal cerebral vein was quite distinct without the inconvenience of overlapping with cerebral cortical veins, to its advantage. It is also suitable for comfirmation of the venous angle.

For the measurement of the position of the venous angle, however, the limitation on the site of standard points in tomography is under disadvantage.

Piepgras ${ }^{4}$ recognized the diagnostic significance of angiotomography in cases of aneurysm of anterior communicating artery. In the diagnosis of cerebral aneurysm, radiography in the direction of antero-posterior, lateral and oblique view as well as submentovertical view may be performed. With addition of angiotomography, useful reference is added for the operative approach.

In diseases with congenital anomalies, especially anomaly on the median plane or around the third ventricle, diagnosis through pneumoencephalography is frequently performed. Through conducting angiotomography following pneumoencephalography, accurate grasping of the relationship between internal cerebral vein and congenital anomaly would make the diagnosis more precise. This procedure should be performed in cases of cavum veli interpositi and others.

In angiotomography, paucity of significance of antero-posterior tomography as compared with lateral tomography and increase of the amount of opaque media might represent drawbacks of this method. Simplification and propagation of the apparatus, however, would result in further developement of cerebral angiotomography.

\section{SUMMARY}

In 63 cases, angiotomography was performed during cerebral angiography. These findings were described and the purpose, significance and indication discussed.

The apparatus for radiography was CGR Princeps 50 cephalography apparatus, with the angle of swing of $30^{\circ}$.

This is quite useful for visualization of deep cerebral vein especially internal cerebral vein.

When indication such as cerebral aneurysm, brain tumor and congenital anomaly are adequately selected, vascular density is not interfered with bone density and difficulty for interpretation to overlapping of blood vessels is solved. 


\section{REFERENCES}

1. Du Boulay, G. H. and Jackson, D. C. (1965) Cranial angiotomography. Clinical Radiology. 16: 148-153.

2. Johansen, C. (1954) The central vein and deep dural sinuses of the brain, an anatomical and angiographic study. Acta Radiol. Suppl. 107: 1-184.

3. Moniz, E. (1927) L'encephalographie arterielle son importance dans la localisation des tumeurs cerebrales. Rev. Neurol, 34: 72-89.

4. Piepgras, U., Pampus, F., and Heuck, F. (1968) Der Wert der Simultanen Angiographie für die Diagnostik von Hirngefaessaneurysmen. Forts. geb. Roentgenstrahlen. 108: 170-176.

5. Rocea, P. and Rosadini, G. (1960) Tecnica di angiostratigrafia cerebrale. G. Psychiat. Neuropath. 88: 371-383.

6. Rocca, P. and Rosadini, G. (1961) Cerebral angiostratigraphy: First practical results. Radiol. 73: 223-227.

7. Rosadini, G, and Rocca, P. (1963) Simultane mehrschitige Tomographie und ihre Anwendung in der Gehirnagiographie. Acta Radiol. Diagnosis. 1: 385-388.

8. Toya, S., Murase, I., and Nakanishi, T. (1968) Tomography in cerebral angiography and pneumoencephalography. Presented at The 27th Congress of Japan Neurosurgical Society, Tokyo. (in Japanese)

9. Toya, S., Murase, I., and Nakanishi, T. (1970) Significances of tomography in cerebral angiography and pneumoencephalography. Presented at The 29th Congress of Japan Neurosurgical Society, Sapporo. (in Japanese)

10. Wolf, B. S., Newman, C. M., and Selginger, B. (1955) The diagnostic value of the deep cerebral vein in cerebral angiography. Radiol. $64: 161-177$.

\section{EXPLANATION OF FIGURES}

Fig. 1. Normal cerebral angiogram.

a. Standard angiogram, lateral view. Anterior and middle cerebral artery are visualized.

b. Angiotomogram, lateral view. Anterior cerebral artery is well visualized without a shadow of middle cerebral artery.

Fig. 2. Internal cerebral vein in angiotomography, lateral view.

Fig. 3. Deep cerebral vein in angiotomography, lateral view.

Fig. 4. Saccular aneurysm of distal portion of anterior cerebral artery. Angiotomography, lateral view.

Fig. 5. Aneurysm of internal carotid artery. Angiotomography, lateral view.

Fig. 6. Microangioma in the peripheral portion of right lenticulostriate artery.

a. Standard angiogram, antero-posterior view. Microangioma in the peripheral portion of right lenticulostriate artery was suspected (arrow).

b. Angiotomogram, antero-posterior view. Micro angioma in the peripheral portion of right lenticulostriate artery is well visualized (arrow). 


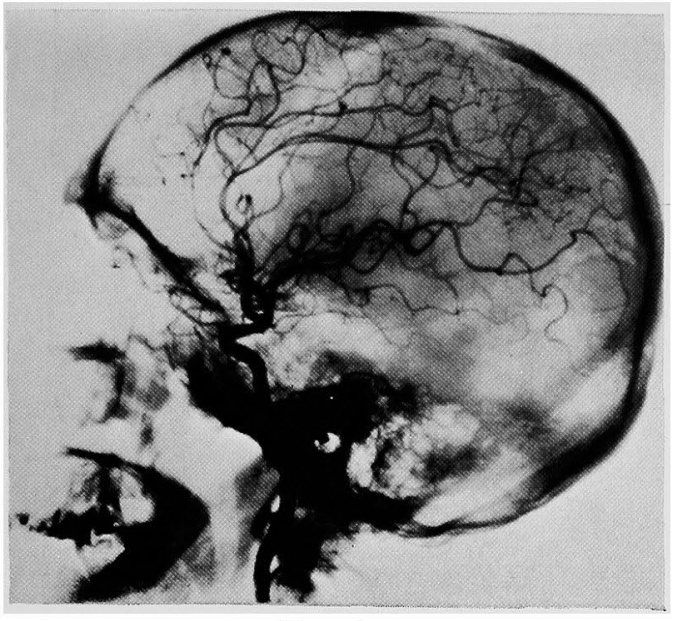

Fig. 1 a

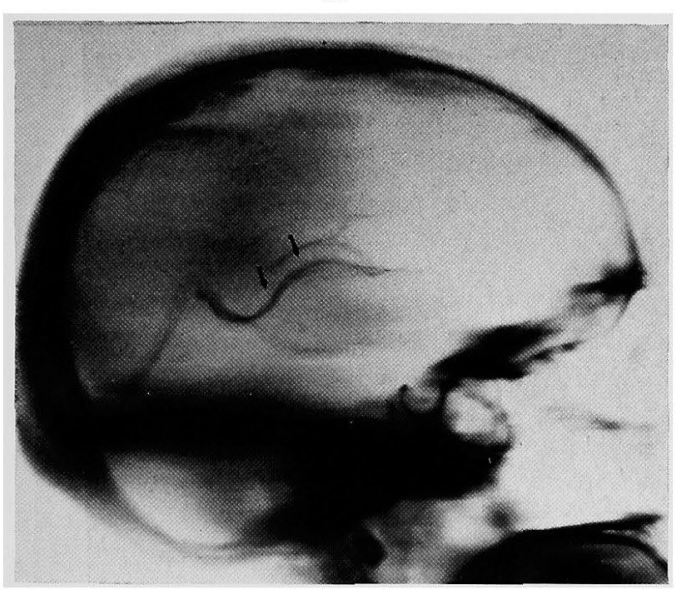

Fig. 2

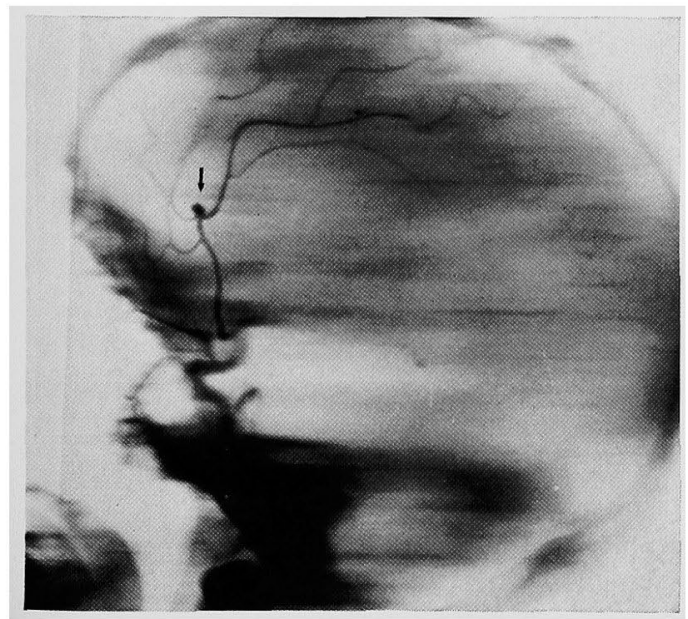

Fig. 4

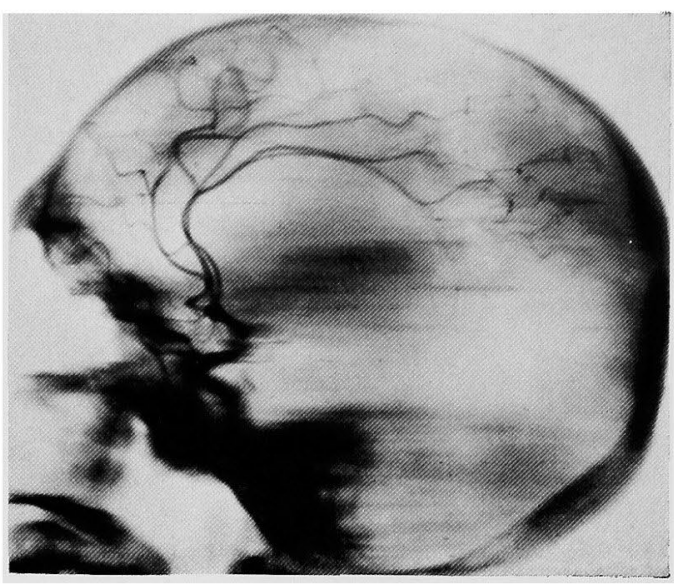

Fig. 1 b

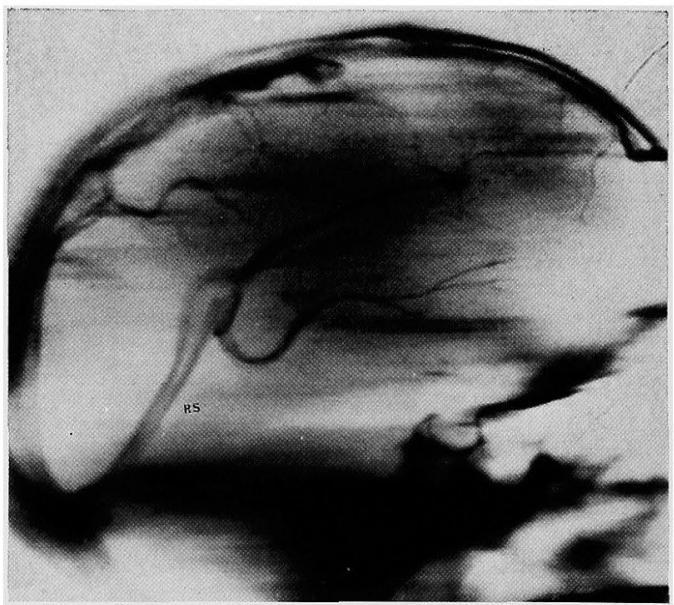

Fig. 3

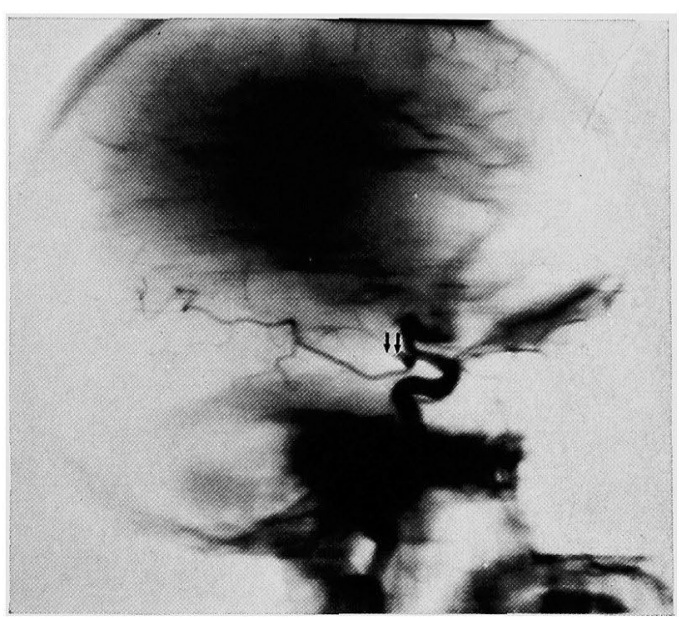

Fig. 5 

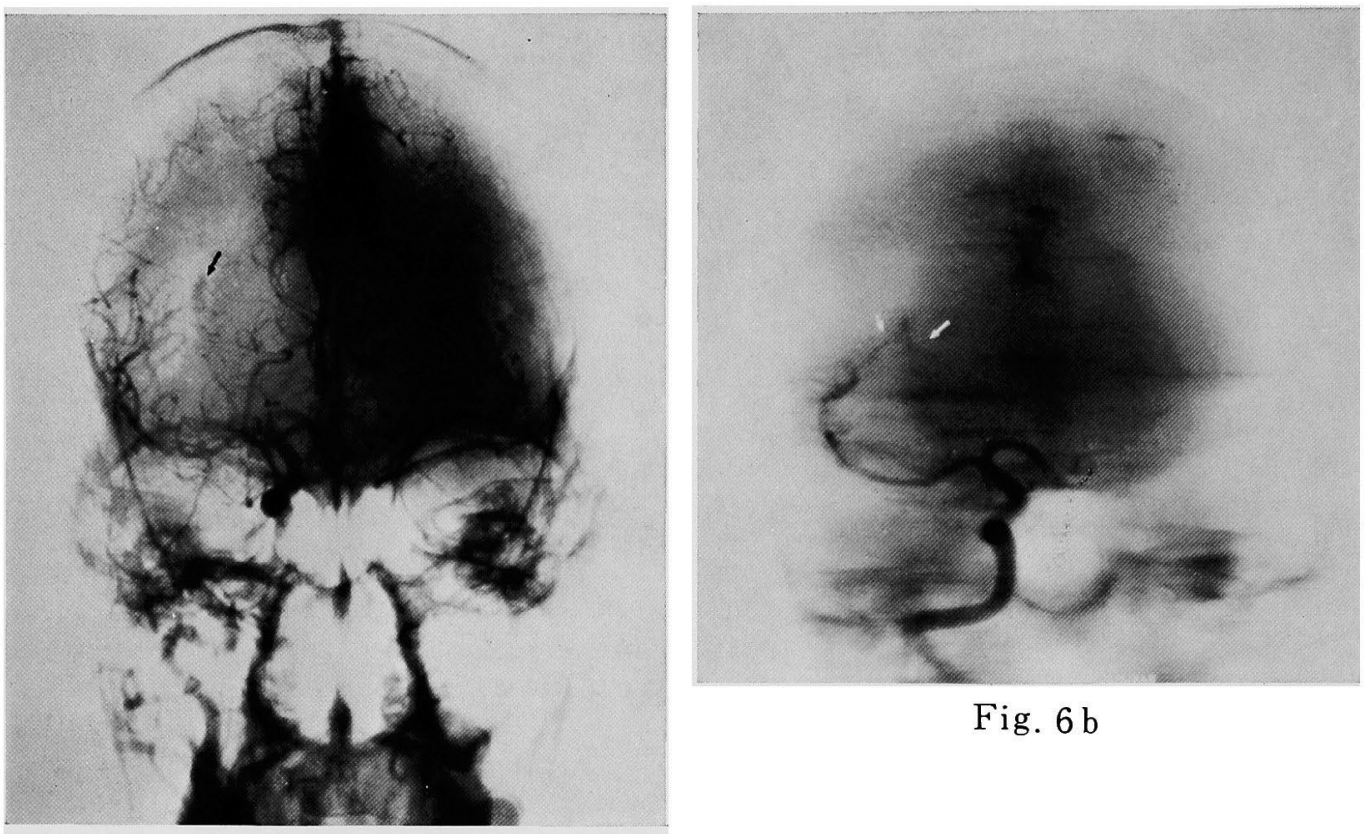

Fig. 6 b

Fig. 6 a 